\title{
Tras las huellas de Ruth Mary Kelly: feminismo y prostitución en la Buenos Aires del siglo XIX
}

Daich, Deborah. (2019). Tras las huellas de Ruth Mary Kelly: feminismo y prostitución en la Buenos Aires del siglo XIX. Ciudad Autónoma de Buenos Aires: Biblos.

\section{Estefanía Martynowskyj ${ }^{1}$}

1 Universidad Nacional de Mar del Plata, CONICET. Centro de Estudios Sociales y Políticos, Facultad de Humanidades. Mar del Plata, Argentina

Correo electrónico: estefania_mdp@hotmail.com

Las "prostitutas" suelen ser un sujeto ausente en la historia del feminismo. Cualquiera que se haya interesado en la genealogía de este movimiento lo sabe; son objeto de grandes debates, pero rara vez aparecen como sujeto. Sin embargo, las "prostitutas" siempre han estado allí, sus colectivas han nacido en el seno del feminismo, ya sea que se reconozcan como trabajadoras sexuales o como víctimas de la explotación sexual. Como han señalado Cecilia Varela y Santiago Morcillo en su traducción de Inventing Sex Work, de Carol Leigh, se trata de una filiación borrada. Por ello ir "tras las huellas" de su participación en el movimiento feminista implica un trabajo de arqueología; hace falta "excavar" en la memoria de las militantes reconocidas y en un ecléctico abanico de fuentes -que incluye fotografías, fanzines, notas en revistas y diarios, material audiovisual-, para poder identificar su presencia y traerla al presente. Eso es lo que ha hecho Deborah Daich en este precioso libro con Ruth Mary Kelly, una prostituta portuaria de la ciudad de Buenos Aires, pionera en plantear que la prostitución era un un trabajo que hacían las mujeres y en luchar por sus derechos laborales en Argentina.

El contexto presente en el que se reorganizan las experiencias pasadas que la autora narra es el de la consolidación y el crecimiento del gremio de las trabajadoras sexuales y la emergencia de las putas feministas, en medio de un encendido debate sobre el estatuto de la prostitución, su vinculación con las desigualdades de género y la forma en que se inserta en las demandas del feminismo, en un escenario global de campañas antitrata que trazan una relación lineal entre este delito y la prostitución, a la que caracterizan siempre y de antemano como violencia de género. De modo que, al traer al presente a Ruth, Daich interroga nuestras genealogías feministas y traza los antecedentes del movimiento local de trabajadoras sexuales.

El libro constituye un esfuerzo por alejarse de las perspectivas victimizantes de la "prostitución", que opacan a las mujeres como sujetos de acción. Por el contrario, traza la historia de una "mujer pública", que, en tanto "prostituta" y feminista, transgredió los mandatos de género. No por ello la autora construye una representación idealizada de Ruth, sino que la retrata con todas

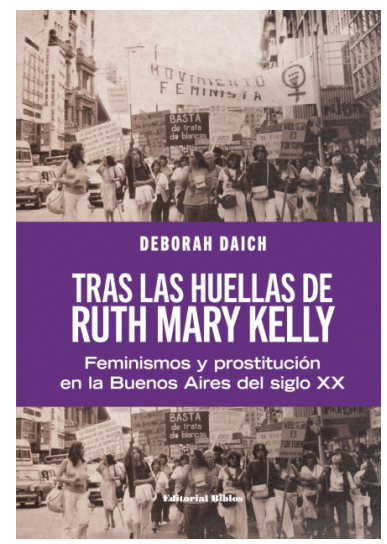


sus contradicciones y matices, moviéndose en un ambiente que refleja las desigualdades y las jerarquías de la sociedad que lo contiene. El entramado de sociabilidad que tenía lugar en el puerto donde Ruth ejercía la prostitución era tanto el escenario de relaciones de amistad y romance, como de historias de engaños y violencias. A pesar de que estuvieran presentes en sus memorias, publicadas en 1972 por el periodista Julio Ardiles Gray bajo el nombre Memorial de los infiernos, y en las entrevistas que dio para distintos medios, Ruth era clara en identificar la violencia institucional que sufría por su oficio como la más cruel.

Daich se detiene en el perfil escandaloso de Ruth Mary Kelly, que no perdía oportunidad para decir en público que era "prostituta". A contramano de los que ven allí un síntoma de problemas psicológicos o el resultado de una vida dura y sufrida, la autora destaca el carácter político de estas performances. Cuando Ruth se subía a los techos a formular algún reclamo o se presentaba ante cualquiera como prostituta o trabajadora del sexo, sin importar cuán importante pudiera ser el/la interlocutor/a -llegó a gritárselo a Raúl Alfonsín el día que asumió la presidencia-, revertía temporalmente una situación de desigualad. Podía negociar ciertas demandas que en un principio parecían negadas o simplemente interpelar el imaginario sociosexual y a sus interlocutores/as, produciendo incomodidad al señalar la hipocresía y la doble moral sexual de una sociedad desigual en términos de clase y de género. Haciendo escándalo, Ruth expresaba su rebeldía y revelaba "verdades incómodas", y lo hacía de manera constante porque, como relatan sus entrevistadas, "Ruth estaba en todas partes", "ella se metía con todos".

Daich se detiene en los espacios que Ruth transitó durante las décadas de 1970 y 1980 y nos muestra una mujer que hizo del nomadismo una estrategia política y una marca personal. Aunque no perteneció a ninguna agrupación en particular, indiscutiblemente formó parte del feminismo. Sus reivindicaciones quedaron en la memoria de quienes la conocieron, en los reportajes que dio y en el Memorial de los infiernos. Le preocupaban las condiciones de trabajo de las prostitutas en los burdeles, acceder a una obra social y a la jubilación, y fundamentalmente poder ejercer su oficio sin ser acosadas y violentadas por la policía. Esto último la acercó al Frente de Liberación Homosexual (FLH) y al Grupo Política Sexual (GPS), ya que tanto las prostitutas como los homosexuales eran el blanco privilegiado de los edictos policiales. Allí se vinculó con Néstor Perlongher y expandió sus ideas sobre la prostitución y la sexualidad. Quienes la frecuentaron en ese contexto recuerdan que cambió su presentación de "prostituta" a "productora de orgasmos" y "proletaria del sexo".

También se relacionó con las feministas de la Unión Feminista Argentina (UFA) y del Movimiento de Liberación Femenina (MLF). Participó de innumerables eventos, reuniones y acciones, y todas dicen recordarla con gran afecto. Sin embargo, la falta de registro que encuentra Daich entre las feministas en relación con los reclamos laborales que planteaba Ruth la llevan a preguntarse por los límites de la escucha, a los que vincula con los límites de la sororidad esgrimida. Que la prostitución no fuera un tema, como sostienen una y otra vez las entrevistadas de Daich, estando Ruth allí, da cuenta de que la distancia, en términos de clase y sexualidad, que la separaba de las feministas -a quienes llamaba señoras cuando se enojaba- ponía en evidencia la ficción de la experiencia compartida de opresión. Si bien las feministas reconocían el estigma de "puta" como un mecanismo del patriarcado para dividir a las mujeres y controlar su sexualidad y comportamientos, y estaban de acuerdo con la necesidad de dar batalla a la represión policial y a la explotación de 
la prostitución, no podían aceptar que Ruth no se reconociera como víctima. Daich rastrea las perspectivas teóricas que informaron a estas militantes en las décadas de 1970 y 1980, indagando en los materiales que circularon entre ellas, en las traducciones que hicieron y en lo que publicaron en las revistas que editaban. Si bien en Estados Unidos y Europa tenían lugar las llamadas guerras del sexo, que enfrentaban a las feministas culturales provenientes del movimiento antipornografía y a las prosexo o anticensura -aliadas de las trabajadoras sexuales-, a la Argentina solo llegó la perspectiva de las primeras. De modo que el feminismo se configuró como sinónimo de abolicionismo y la prostitución se entendió como la institución por antonomasia de la dominación masculina, una esclavitud sexual de la mujer. Señala la autora que el acercamiento de Ruth al FLH y al GPS pudo haberla acercado a los procesos organizativos que a mediados de 1970 emergieron en otros países, que también pueden haberle llegado a través del puerto. Pero lo cierto es que Ruth tempranamente, a principios de esa década, y en sintonía con la perspectiva de las feministas marxistas nucleadas en la campaña Wages for Housework, ubicaba a la prostitución en el contexto más amplio de la explotación de todas las mujeres en el capitalismo, y por ende pensaba a las prostitutas como parte de la clase trabajadora.

Los límites en la escucha dentro del movimiento feminista llevaron a Ruth a transitar por otros espacios. Daich sigue sus huellas entre los anarquistas y los punks, el movimiento de derechos humanos, los partidos políticos y los sindicatos. Su circulación constante se condecía con su búsqueda de libertad. Muestra la autora que, por donde pasaba, se transformaba y transformaba a los demás, desestabilizando los términos de las discusiones, visibilizando temas que no eran centrales en la vida pública de ese entonces.

Al igual que Ruth, Deborah Daich trae a la escena local -atravesada por la campaña antitrata- un tema que incomoda a gran parte del movimiento feminista porque desestabiliza las genealogías que pretenden borrar a las trabajadoras sexuales de nuestra historia, poniendo en cuestión la homogeneidad del sujeto "mujer" que las sustentan. Las huellas de Ruth que este libro rastrea se empalman con el camino trazado por las trabajadoras sexuales organizadas desde 1995 y nos invitan a ampliar nuestros horizontes políticos para que en el feminismo quepamos todxs. 
